Conclusion: Women with scoliosis showed significantly higher fracture risk for major osteoporotic fractures and for hip fractures compared to those without scoliosis.

References:

[1] https://www.sheffield.ac.uk/FRAX/index.aspx

[2] Mao YF, Zhang Y, Li K, et al. Discrimination of vertebral fragility fracture with lumbar spine bone mineral density measured by quantitative computed tomography. J Orthop Translat. 2018;16:33-39. Published 2018 Oct 10. doi:10.1016/j.jot.2018.08.007.

[3] Sabo A, Hatgis J, Granville M, Jacobson RE. Multilevel Contiguous Osteoporotic Lumbar Compression Fractures: The Relationship of Scoliosis to the Development of Cascading Fractures. Cureus. 2017;9(12):e1962. Published 2017 Dec 19. doi:10.7759/cureus. 1962.

[4] Kirilova E, Cherkezov D, Gonchev B, Zheleva Z. OSIRIS Index for the assessment of the risk for osteoporosis in menopausal women, National conference with international participation, 6-7 october 2019, Kardzhali "Science and society 2019", RKR print OOD ISSN 1314-3425

[5] Madzharova R, Kirilova E, Petranova T, Nikolova M. Assessment of the activity for self care in women with osteoporosis, Science and TechnologieVolume VIII, 2018, Number 1: MEDICAL BIOLOGY STUDIES, CLINICAL STUDIES, SOCIAL MEDICINE AND HEALTH CARE,1-6.

[6] Chaklin VD, Orthopedy - Moscow: Medgiz - 1965 - C. 209

[7] Chaklin VD. Pathology, clinical manifestation and treatment of the scoliosis, $1^{\text {st }}$ congress of the union of the orthopedists and traumatologists, Moscow: Medgiz, 1957 - T.2. - p 798

Disclosure of Interests: None declared

DOI: 10.1136/annrheumdis-2020-eular.4440

\section{SAT0474 \\ WHAT DETERMINES THE EFFECT OF THERAPY WITH DENOSUMAB ON BONE IN WOMEN WITH RHEUMATOID ARTHRITIS AND OSTEOPOROSIS}

P. Kovalenko ${ }^{1}$, I. Dydykina ${ }^{1}$, A. Smirnov ${ }^{1}$, E. Nasonov ${ }^{1} .{ }^{1}$ V.A. Nasonova Research Institute of Rheumatology, Moscow, Russian Federation

Background: RANK-ligand is essential for osteoclast development, activation, and survival and it is a key mediator of increased osteoclast activity in rheumatoid arthritis (RA). Denosumab is a monoclonal antibody that binds RANK-ligand. Objectives: The aim of this study was to evaluate the effects of denosumab on bone mineral density (BMD) and to define a contribution of factors: anamnesis, clinical/laboratory markers, glucocorticoids (GC) intake, etc. on the response to therapy with denosumab in women with RA and osteoporosis (OP).

Methods: 66 postmenopausal women (mean age 59,6 $\pm 7,4$ ) with RA (mean duration $17,7 \pm 10,4$ years) and OP received s/c denosumab $60 \mathrm{mg}$ every 6 months pro 12 months. RF-positive were $72 \%$, ACCP - 74\% of patients. 34 (49\%) patients continued GC. At baseline and after 12 months it was carried out the dual energy x-ray absorptiometry at 3 sites: lumbar spine (L1-L4), hip neck (HN) and distal forearm (DF) and x-ray of hands and feet (Sharp/van der Heijde (SVH) score). The Statistica 6.0 was used.

Results: After therapy it was noted the increase $(p<0,05)$ of BMD in L1-L4 and $H N$, a tendency to increase ( $p=0,0529)$ in DF. Mean BMD (L1-L4) beforelafter the treatment was $0,821 \pm 0,104 \mathrm{~g} / \mathrm{cm}^{2}$ vs $0,864 \pm 0,110 \mathrm{~g} / \mathrm{cm}^{2}$, at $\mathrm{HN}$ was 0,625 $\pm 0,089 \mathrm{~g} / \mathrm{cm}^{2}$ vs $0,639 \pm 0,088 \mathrm{~g} / \mathrm{cm}^{2}$, at DF was $0,498 \pm 0,090 \mathrm{~g} / \mathrm{cm}^{2}$ vs $0,503 \pm$ $0,089 \mathrm{~g} / \mathrm{cm}^{2}$. The mean change of BMD (\%) after 12 months at L1-L4 was $+4,6 \%$, at $\mathrm{HN}+2,8 \%$, at $\mathrm{DF}+0,7 \%$. Positive response (increase or stabilization of BMD) was noted in $89 \%$ patients at L1-L4, 67\% - at HN and $60 \%$ - at DF. Analysis of influence of various factors (statistically significant) on the response to therapy is presented in the Table.

Conclusion: After 12 months of therapy with denosumab in postmenopausal women with RA and OP it was shown the significant increase of BMD in L1-L4

Table. Influence of various factors on the response to therapy with denosumab after 12 months of treatment $(n=66)$

\begin{tabular}{|c|c|c|}
\hline DXA site & $\begin{array}{l}\text { Positive response on therapy is } \\
\text { associated with }\end{array}$ & $\begin{array}{l}\text { Negative response on therapy is } \\
\text { associated with }\end{array}$ \\
\hline L1-L4 & - & $\begin{array}{l}\text { - GC intake (>3 months in anamne- } \\
\text { sis) }(p=0,034) \\
\text { - the beginning of GC intake after } \\
\text { menopause }(p=0,023)\end{array}$ \\
\hline Hip neck & $\begin{array}{l}\text { - higher concentration of the RF } \\
\text { (initially and in dynamics) }(p< \\
0,05) ; \\
\text { - the beginning of menopause later } \\
\text { than RA onset }(p=0,024)\end{array}$ & $\begin{array}{l}\text { - GC intake (>3 months in anamne- } \\
\text { sis) }(p=0,024)\end{array}$ \\
\hline $\begin{array}{l}\text { Forearm } \\
\text { (distal 1/3) }\end{array}$ & - RF-positivity $(p=0,02)$ & $\begin{array}{l}\text { - back correlates with increase in } \\
\text { erosion score and total SVH score } \\
r=-0,360(p<0,05)\end{array}$ \\
\hline
\end{tabular}

and $\mathrm{HN}$, a tendency to increase in DF. The mean change of BMD (\%) after 12 months was $+4,6 \%$ at L1-L4, at $\mathrm{HN}+2,8 \%$, at $\mathrm{DF}+0,7 \%$. Positive response on denosumab (BMD) was noted in $89 \%$ patients at L1-L4, 67\% - at HN and $60 \%$ - at DF. Analysis of influence of factors on the response to therapy showed that positive response on therapy in $\mathrm{NH}$ and DF was associated with RF-positivity. The distinct contribution to the negative response in L1-L4 and $\mathrm{HN}$ was associated with GC intake (previous intake more than 3 months in the anamnesis) and purpose of the GC after menopause onset. Also, negative response in DF back correlated with increase in erosion score and total SVH score.

Disclosure of Interests: None declared

DOI: 10.1136/annrheumdis-2020-eular.2301

\section{SAT0475 \\ DENOSUMAB VERSUS ORAL BISPHOSPHONATE FOR OSTEOPOROSIS IN LONG-TERM GLUCOCORTICOID USERS: A 12-MONTH RANDOMIZED CONTROLLED TRIAL}

C. C. Mok ${ }^{1}$, L. Y. Ho ${ }^{1}$, K. L. Chan ${ }^{1}$, S. M. Tse ${ }^{1}$ on behalf of N/A. ${ }^{1}$ Tuen Mun Hospital, Medicine, Hong Kong, Hong Kong (SAR)

\section{Background:}

Objectives: To compare the efficacy of denosumab (DEN) and oral alendronate (ALN) on spinal bone mineral density (BMD) in long-term glucocorticoid users. Methods: Patients receiving long-term prednisolone treatment for medical illnesses were recruited. Inclusion criteria: (1) adult patients $\geq 18$ years of age; (2) prednisolone $\geq 2.5 \mathrm{mg} /$ day for $\geq 1$ year. Exclusion criteria: (1) previous use of DEN, teriparatide; (2) plan for pregnancy; (3) metabolic bone disease or unexplained hypocalcemia; (4) renal insufficiency. Participants were randomized to receive either: (1) DEN (60mg subcutaneously every 6 months); or (2) ALN (70mg/week). Calcium (Caltrate $3000 \mathrm{mg} /$ day) and vitamin D3 (cholecalciferol 1000IU/day) was given. BMD (femoral neck, total hip, lumbar spine) at month 0, 6 and 12 months were performed. Markers of bone turnover (serum P1NP and CTX) were also assayed at the same time points. The primary outcome was the difference of lumbar spine BMD change at month 12 between the two groups.

Results: 139 subjects were recruited (age 50.0 12.7 years): 69 assigned DEN and 70 assigned ALN. Underlying medical diseases: SLE (81\%), RA (9.4\%) and myositis $(5 \%)$. Prednisolone dose at entry was $5.7 \pm 2.1 \mathrm{mg} /$ day. $56 \%$ of female patients were postmenopausal. $73(53 \%$ ) of patients were osteoporotic (T score $<-2.5)$ at the hip, femoral neck or lumbar spine. The mean body mass index (BMI) was $23.1 \pm 4.1 \mathrm{~kg} / \mathrm{m} 2$ (11\% patients had $\mathrm{BMl}<18 \mathrm{~kg} / \mathrm{m} 2) .82(59 \%)$ patients were naive to bisphosphonates. Pre-existing fragility or vertebral fracture was present in $19(14 \%)$ patients and 18 patients $(13 \%)$ had a family history of fractures. Baseline demographic data, osteoporotic risk factors, and BMD at various sites were not significantly different between the two groups at entry. At month 12 , a significant gain in BMD at the lumbar spine $(+3.5 \pm 2.5 \% ; p<0.001)$ and the hip $(+0.9 \pm 2.8 \% ; p=0.01)$ was observed in DEN-treated patients, whereas the corresponding change was $+2.5 \pm 2.9 \%(p<0.001)$ and $+1.6 \pm 2.7 \%(p<0.001)$ in the ALN group. The spinal BMD at month 12 was significantly higher in the DEN than ALN group after adjustment for BMD values at baseline, age, sex and other osteoporosis risk factors that included smoking, drinking, cumulative steroid doses in one year, BMI, menopausal status and personal history of fracture $(p=0.045)$. The differences in hip and femoral neck BMD were not significantly different between the two groups after adjustment for the same confounding factors. No new symptomatic fractures occurred in any participants at month 12. Adverse events were similar in frequency between the two treatment arms Major infective episodes were uncommon (0.06/patient/year) and similar in the two groups. Minor upper gastrointestinal symptoms and non-specific dizziness were numerically more common in the ALN but arthralgia, minor infections (eg. upper respiratory tract) and new hypertension was more commonly reported in the DEN group. Three patients from ALN and 2 patients from DEN group were withdrawn from the study because of non-compliance but none withdrew because of adverse events.

Conclusion: In patients receiving long-term glucocorticoids, DEN is superior to ALN in raising the spinal BMD after 12 months' treatment. Both DEN and ALN were well tolerated.

Acknowledgments: NIL

Disclosure of Interests: None declared

DOI: 10.1136/annrheumdis-2020-eular.4679

\section{SAT0476 COMPLIANCE AND PERSISTENCE OF ANTI- OSTEOPOROTIC TREATMENTS IN PATIENTS WITH HIP FRACTURE}

S. Paredes ${ }^{1}$, M. Guinovart ${ }^{2}$, A. Basco ${ }^{2}$, C. Llop ${ }^{2}{ }^{1}$ Hospital Universitari Sant Joan de Reus, Department of Rheumatology, Reus, Spain; ${ }^{2}$ CatSalut, Pharmacy Unit, Tarragona, Spain 